\title{
Human immunodeficiency virus type I efficiently binds to human fetal astrocytes and induces neuroinflammatory responses independent of infection
}

\author{
Jinliang Li ${ }^{1}$, , Galina Bentsman ${ }^{1}$, Mary Jane Potash ${ }^{1}$ and David J Volsky*1
}

Address: ${ }^{1}$ Molecular Virology Division, St. Luke's-Roosevelt Hospital Center and Columbia University, 432 West 58 th Street, New York, NY 10019 , USA and 'Beckman Research Institute of the City of Hope, Division of Virology, 1500 East Duarte Road, Duarte, CA 91010-3011, USA

Email: Jinliang Li - JiLi@coh.org; Galina Bentsman - itotillo@chpnet.org; Mary Jane Potash - mjp6@columbia.edu; David J Volsky* - djv4@columbia.edu

* Corresponding author

Published: 12 May 2007

BMC Neuroscience 2007, 8:31 doi:10.1/86/147|-2202-8-31
Received: I December 2006

Accepted: 12 May 2007

This article is available from: http://www.biomedcentral.com/|47|-2202/8/3 I

(C) $2007 \mathrm{Li}$ et al; licensee BioMed Central Ltd.

This is an Open Access article distributed under the terms of the Creative Commons Attribution License (http://creativecommons.org/licenses/by/2.0), which permits unrestricted use, distribution, and reproduction in any medium, provided the original work is properly cited.

\begin{abstract}
Background: HIV-I infects human astrocytes in vitro and in vivo but the frequency of infected cells is low and its biological significance is unknown. In studies in vitro, recombinant gp/20 alone can induce profound effects on astrocyte biology, suggesting that HIV-I interaction with astrocytes and its functional consequences extend beyond the limited levels of infection in these cells. Here we determined the relative efficiencies of HIV-I binding and infection in human fetal astrocytes (HFA), mainly at the single cell level, using HIV-I tagged with green fluorescence protein (GFP)-Vpr fusion proteins, termed HIV-GFP, to detect virus binding and HIV-I expressing Rev and NefGFP fusion proteins to detect productive infection.
\end{abstract}

Results: Essentially all HFA in a population bound HIV-GFP specifically and independently of CCR5 and CXCR4. The dynamics of this binding at $37^{\circ} \mathrm{C}$ resembled binding of an HIV fusion mutant to CD4-positive cells, indicating that most of HIV-GFP arrested infection of HFA at the stage of viruscell fusion. Despite extensive binding, only about I\% of HFA were detectably infected by HIVRevGFP or HIV-NefGFP, but this proportion increased to the majority of HFA when the viruses were pseudotyped with vesicular stomatitis virus envelope glycoprotein $G$, confirming that HFA impose a restriction upon HIV-I entry. Exposure of HFA to HIV-I through its native proteins rapidly induced synthesis of interleukin- 6 and interleukin- 8 with increased mRNA detected within $3 \mathrm{~h}$ and increased protein detected within $18 \mathrm{~h}$ of exposure.

Conclusion: Our results indicate that HIV-I binding to human astrocytes, although extensive, is not generally followed by virus entry and replication. Astrocytes respond to HIV-I binding by rapidly increased cytokine production suggesting a role of this virus-brain cell interaction in HIV-I neuropathogenesis. 


\section{Background}

Human immunodeficiency virus type 1 (HIV-1) infection is associated with a spectrum of neurological diseases of varying severity including the endstage syndrome HIVassociated dementia (HAD) [1]. Although the core pathophysiological defects of HAD are neuronal damage and loss of specific neuronal populations [1-4], neurons rarely show evidence of HIV-1 infection [5-7]. It is generally accepted that HIV-1 can be neuropathogenic through synthesis of viral proteins that are directly neurotoxic as well as through an array of cellular toxins that are produced by HIV-1-infected cells (reviewed in $[8,9]$ ). Particularly in the case of HAD with encephalitis, it is clear that HIV-1infected macrophages contribute greatly to disease (reviewed in $[8,10,11])$. In various model systems and in HIV-1-infected humans, multiple products of macrophages have been associated with neuropathogenesis including arachidonic acid metabolites, IL-6, MCP-1, platelet activating factor, and TNF- $\alpha$ [12-16].

There is growing interest in the potential role of astrocytes in HIV-1-mediated neuropathogenesis. Astrocytes are an abundant [17] and heterogeneous [18,19] population of cells of neuroectodermal origin which perform many essential functions in the brain, from structural and metabolic support, responses to brain injury and innate immune reactions, control of extracellular glutamate, to regulation of neuronal cell activities and neural signaling (reviewed in [20-23]). Astrogliosis, the presence of activated and hypertrophied astrocytes, is a defining neuropathological characteristic of $\operatorname{HAD}[24,25]$. There is also evidence of HIV-1 infection in a small and variable fraction of astrocytes in vivo, particularly in advanced brain disease [7,26-30]. The significance of these overt astroglial pathologies is unknown but overall, unlike neurons, astrocytes rarely die in HIV-1-infected brains [31,32]. Productive infection of human astrocytes with HIV-1 has significant effects on cell physiology in vitro [33,34] and it associates with measurable neuropathology in a mouse model [35], suggesting that infected astrocytes, although infrequent, can have localized pathogenic effects.

Growing evidence suggests that astrocytes also may suffer dysregulation in the HIV-1-infected brain that may extend beyond the limited levels of HIV-1 infection and contribute to neuropathogenesis in distinct pathways (reviewed in [21,36-38]). As part of brain parenchyma, astrocytes are likely exposed continuously to HIV-1 particles, viral proteins, cytokines, and other substances secreted by HIV-1infected macrophages and microglia. Although they lack CD4 they express CXCR4, and under certain circumstances, CCR3 and CCR5, the co-receptors for HIV-1 entry into cells (reviewed in [39-41]). These chemokine receptors can transduce responses to chemokines and to HIV-1 gp120 present in the brain and they might be involved in
HIV-1 association with astrocytes. Studies in vitro indicate that many of these products significantly modulate astrocyte physiology which in turn can alter essential interactions of astrocytes with other cells in the brain, particularly neurons. For example, exposure of cultured astrocytes to HIV-1, recombinant gp120, or viral transactivator Tat induces some of the same secretable mediators of neuropathogenesis as those produced by macrophages, including inflammatory cytokines TNF- $\alpha$ and IL-1 $\beta$, chemokines MCP-1 and IP-10, IL-6, or neurotoxin nitric oxide [42-50]. The apparent dysregulation of astrocyte immune functions could contribute to the overall inflammatory environment in the brain. In other studies in culture, intact HIV-1 or exogenous gp120-induced extensive changes in astrocyte gene expression [38,51-53] and impaired transport of extracellular glutamate by astrocytes [54,55], a defect which may lead to neuronal death by glutamate excitotoxicity [20]. Glutamate uptake can also be impaired by intracellular expression of recombinant Tat or exposure of astrocytes to TNF- $\alpha$ [56,57]. In another potential neurotoxic mechanism, recombinant gp 120 was shown to induce $\mathrm{Ca}^{++}$-dependent glutamate secretion by astrocytes and neuronal cell death in glial-neuronal cocultures in a pathway involving signaling through CXCR4 and production of TNF- $\alpha[58,59]$. Overall, these findings suggest that astrocytes rendered dysfunctional by exposure to HIV-1 in the brain have the capacity to injure or impair neurons. Because both HIV-1 binding and native infection can affect astrocyte function in vitro and in vivo $[33,35,55]$, astrocytes have a pathogenic potential that exceeds their susceptibility to HIV-1 infection.

The interaction of HIV-1 with astrocytes is somewhat paradoxical. Astrocytes do not express surface CD4 but can bind gp120 with high affinity through an unidentified receptor [60,61]. Although exposure to virus or gp120 can globally alter astrocyte function [53-55], HIV-1 infection is highly inefficient compared to T lymphocytes [62-64], a defect which can be attributed to poor virus entry [65-67]. We performed the present study to directly examine the dichotomy between HIV-1 binding and infection in astrocytes, in part by analysis at the single cell level. We constructed several HIV-1 species that either carry or express GFP fused to viral proteins to evaluate binding and infection of primary HFA by fluorescence microscopy. We also used HIV-1 pseudotyped with the envelope glycoprotein $G$ of vesicular stomatitis virus (VSV-G) to efficiently infect CD4-negative HFA [66] to compare productive infection to virus binding for induction of cellular genes. Our results demonstrate that virtually all HFA bind HIV-1 specifically, remarkably stably, and independently of the chemokine receptors CCR3, CCR5, and CXCR4. As previously reported $[68,69]$, fewer than $1 \%$ of HFA were susceptible to HIV-1 infection, but in contrast to some previous studies [70] efficiently expressed Rev-dependent 
viral RNA and cognate protein. Finally we show that HIV1 binding to HFA through gp120 is necessary and sufficient to rapidly induce IL- 6 and increase expression of IL8. Our findings provide strong support for a robust pathway of neuropathogenesis following frequent binding of HIV-1 to astrocytes.

\section{Results \\ Specific and extensive binding of HIV-I by HFA}

In previous studies we inferred that HIV-1 interacts with the majority of HFA because exposure to intact or UVinactivated virus, or recombinant gp120 alone, reduced glutamate uptake by cells and altered cellular gene expression on a population-wide basis $[51,71]$, however such findings are indirect. Using an approach developed by McDonald and colleagues [72], we prepared fluorescently-labeled infectious virions by co-transfection of plasmids encoding intact HIV-1/NL4-3 and a GFP-Vpr fusion protein that is efficiently encapsidated [72] and evaluated this HIV-GFP binding to HFA by fluorescence microscopy. To investigate the specificity of the virus-cell binding, astrocytes were exposed to HIV-GFP in the presence of either unlabeled virus or recombinant soluble CD4 (sCD4) to compete for virion gp120 (Fig. 1). Essentially all HFA bound HIV-1 and this binding was completely blocked by both competitors. To validate our method and reagents, similar studies were carried out with CD4-negative HeLa cells or with MAGI cells, a HeLa derivative engineered to express human CD4 [73] (Fig. 2). HeLa cells failed to bind HIV-1 but MAGI cells bound virus and this inhibition was sensitive to competition by sCD4, indicating that the evaluation of GFP-Vpr-labeled virus binding by microscopy is reliable. These experiments were repeated three times with similar results. We also quantified binding on a population-wide basis by measuring cell-associated p24 $1 \mathrm{~h}$ after HIV-1 exposure to cells at $4^{\circ} \mathrm{C}$ (Fig. 3). The extent of binding is expressed relative to the amount of p24 bound to HFA. MAGI cells bound roughly $40 \%$ p 24 bound to HFA, while CD4-negative $293 \mathrm{~T}$ or HeLa cells bound less than $15 \%$ as much p24 as did HFA. We also exposed HFA to antibodies to the chemokine receptors CCR3, CCR5, or CXCR4, which have been variably detected on HFA [74,75], to test whether any of these receptors are involved in HFA binding of HIV1. There was a modest increase of virus binding after cells were pretreated with anti-CXCR4; the other antibodies had no effect. Taken together our studies demonstrate that HIV-1 labeled through GFP-Vpr interacts specifically with human cells and that the vast majority of HFA are competent to bind HIV-1. Competitors for gp120 block HIV-1 binding to HFA, confirming the specificity of the interaction of HIV-1 with HFA, however our studies do not identify the cellular receptor.

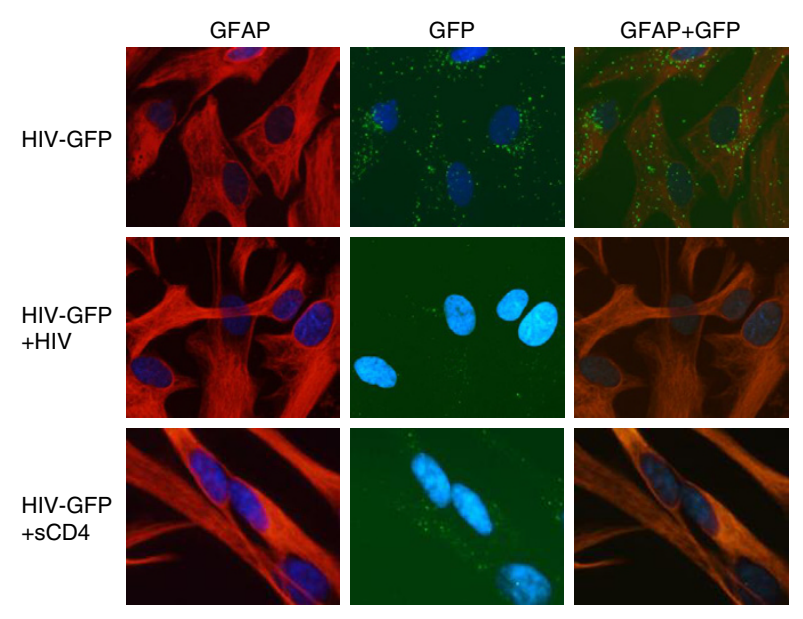

Figure I

Extent and specificity of HIV-I binding to HFA. Primary HFA were exposed for I $\mathrm{h}$ at $4^{\circ} \mathrm{C}$ to NL4-3 carrying GFP-Vpr alone (first row), in the presence of excess unlabeled NL4-3 (second row) or in the presence of soluble CD4 (third row). Cells were stained with anti-GFAP and a Texas Red-labeled secondary antibody to label astrocytes and with DAPI to visualize nuclei. Images of red and green fluorescence were superimposed (third column).

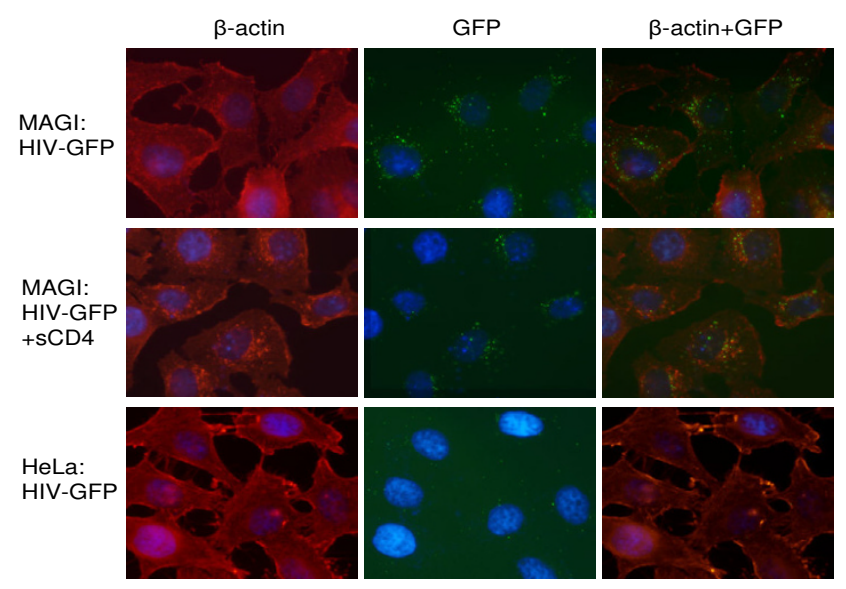

\section{Figure 2}

Extent and specificity of HIV-I binding to CD4-positive and negative HeLa cells. CD4-positive MAGI cells were exposed for I h at $4^{\circ} \mathrm{C}$ to NL4-3 carrying GFP-Vpr alone (first row) or in the presence of soluble CD4 (second row). CD4-negative HeLa cells were exposed to HIV-I/NL43 carrying GFP-Vpr (third row). Cells were stained with anti$\beta$ actin and a Texas Red-labeled secondary antibody and DAPI and images of red and green fluorescence were superimposed (third column). 


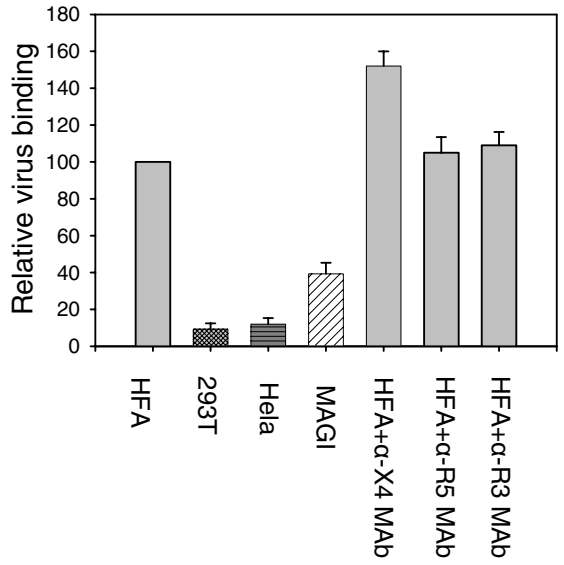

Figure 3

Quantitation and specificity of HIV-I binding to HFA. HFA were exposed for I $h$ at $4^{\circ} \mathrm{C}$ to NL4-3 alone or in the presence of anti-CCR3, anti-CCR5, or anti-CXCR4 antibodies. For comparison, CD4-negative HeLa or 293T cells or CD4-positive MAGI cells were also exposed to NL4-3. HIVI binding, as determined by the amount of p24 core antigen associated with cells, was measured by ELISA. Data are expressed relative to HFA.

\section{HIV-I internalizes poorly in HFA compared to CD4- positive cells}

HIV-1 binding to CD4-bearing lymphocytes is rapidly followed by virus-cell fusion and internalization of the viral nucleocapsid [76]. Since it appears that HFA universally bind HIV-1 (Figs. 1, 2, 3) but they permit limited virus infection $[63,64]$, one defect may lie in post-binding events leading to virus entry. To investigate the internalization of HIV-1 by HFA, we exposed HFA or MAGI cells to HIV-GFP in culture at $37^{\circ} \mathrm{C}$ for various periods of times prior to fixation and observation by fluorescence microscopy (Fig. 4). As a negative control in these studies, we employed 517B-GFP, a mutant of HIV-1 able to bind to but not fuse with cells [77]. HIV-GFP was detected on the surface of both HFA and MAGI cells $1 \mathrm{~h}$ after exposure but subsequently the progress of virus-cell interaction in the two cell types diverged. By $6 \mathrm{~h}$ after exposure the virus was internalized into MAGI cells and appeared to colocalize or overlay intracellular actin; $18 \mathrm{~h}$ after exposure no fluorescent signal was detected in MAGI cells, indicating intracellular breakdown of GFP-Vpr (top panel in Fig. 4). In contrast, bright green fluorescence was detected on astrocytes throughout the $18 \mathrm{~h}$ incubation, a staining pattern very similar to that observed with MAGI cells exposed to fusion-incompetent 517B-GFP (middle and bottom panels in Fig. 4). Longer follow up studies revealed that HIVGFP remains associated with HFA for up to $48 \mathrm{~h}$ after ini- tial exposure without significant loss of the fluorescence signal (data not shown). Similar results were obtained in three independent experiments. These results indicate that HIV-1 binds efficiently and stably to the majority of cells in our HFA cultures and that most of the HFA-bound virus, unlike that bound to MAGI cells, fails to internalize. We cannot definitively localize the GFP-labeled virions by the microscopy method used, but by analogy to fusiondeficient 517B (Fig. 4), one possible reason for inefficient entry of HIV-1 into HFA is that virion binding is not followed by virus-cell fusion, at least for the bulk of virus visualized by our binding method. Under the conditions of these experiments, virion phagocytosis by HFA [78] was not detected but it cannot be excluded.

\section{HIV-I expression occurs in a small subset of HFA}

Previous studies have shown that HIV-1-infected astrocytes express high levels of regulatory viral proteins such as Rev or Nef $[27,63]$ indicating the utility of these protein markers of astrocyte infection. Therefore, to facilitate detection of HIV-1 expressing HFA, we constructed either NL4-3 or fusion-incompetent 517B with genes encoding fusion proteins of GFP with either Nef or Rev to visualize HIV-1 infections at the single cell level in HFA. An additional advantage of these constructs was that since these proteins are not carried in virions, their detection requires new viral protein synthesis by infected cells. HFA were
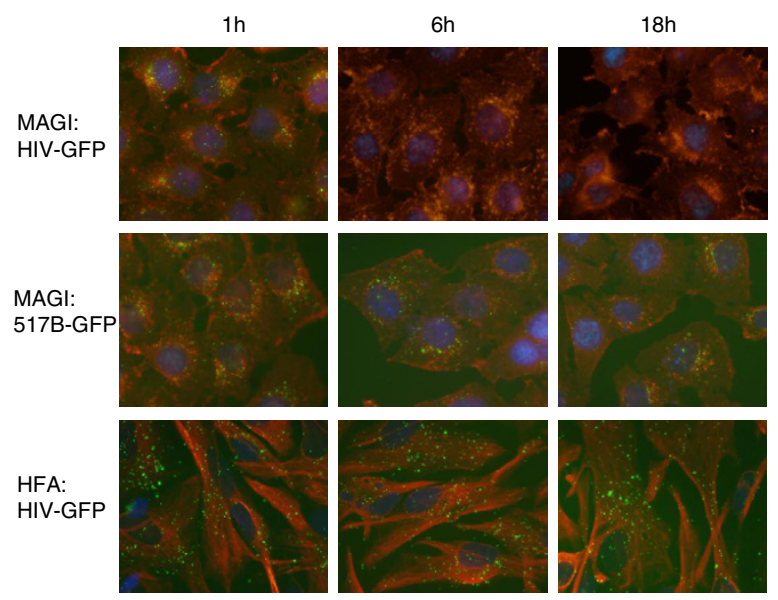

\section{Figure 4}

Dynamics of GFP-Vpr/HIV-I association with HFA or

MAGI cells at $37^{\circ} \mathrm{C}$. MAGI cells were exposed to NL4-3 carrying GFP-Vpr (first row) or to the fusion incompetent HIV-I/5 I7B carrying GFP-Vpr (second row) or HFA were exposed to NL4-3-GFP-Vpr. Cells were incubated with virus at $37^{\circ} \mathrm{C}$ and fixed at $\mathrm{I} \mathrm{h}$ (first column), $6 \mathrm{~h}$ (second column), or $18 \mathrm{~h}$ (third column) after infection. HeLa cells were stained with anti-actin and HFA were stained with antiGFAP, with DAPI and with Texas Red-labeled secondary antibodies. Images shown are superimpositions of red and green fluorescence. 
infected by HIV-NefGFP or HIV-RevGFP or by VSV-G pseudotyped HIV-1 carrying NefGFP and infected cells were examined by fluorescence microscopy $48 \mathrm{~h}$ later (Fig. $5 \mathrm{~A})$. Consistent with our previous study [66], the bulk of HFA could be productively infected by VSV-G pseudotyped HIV-1 as shown in the detection of NefGFP. In contrast, only about $1 \%$ of HFA expressed NefGFP after infection by HIV-1 using its native envelope protein, gp120. To address the issue of the relative expression of structural versus regulatory genes, HFA were infected with virus encoding RevGFP and then were stained for expression of p24 (lower panel in Fig. 5A). All cells that expressed RevGFP also expressed p24 indicating no defect in Rev functions or structural gene expression. To validate this approach, a similar experiment was performed using CD4-positive MAGI cells and the fusion-mutant 517B (Fig. 5B). NefGFP was efficiently expressed after NL4-3 infection but not after 517B expression, indicating that Nef detection required virus entry and synthesis of viral protein. Expression of NefGFP by 517B could be rescued by pseudotyping with VSV-G (lower panel in Fig. 5B), in direct analogy to studies with HFA in Fig. 5A, and confirming that the $517 \mathrm{~B}$ mutation in gp41 prevents the mutant virus internalization and expression [77]. Similar results were obtained in three independent experiments. These results support the interpretation that NefGFP expression is suitable for detection of de novo viral protein synthesis as described for HFA in Fig. 5A.

\section{Induction of cytokines by exposure of HFA to HIV-I}

Previous studies have shown that viral envelope protein gp120 can induce a range of neuroinflammatory products in primary astrocytes in culture $[46,79]$, but intact HIV-1 was tested of this activity only in transformed cell lines $[43,80]$. Here we tested whether HIV-1, consistent with its ability to efficiently bind to HFA, can induce expression of any of a panel of cytokines and chemokines detectable by multi-protein blots (Fig. 6A-C). Culture supernatants from HFA $24 \mathrm{~h}$ after mock infection, infection with VSVG pseudotyped NL4-3 that carries an incapacitating mutation in gp120 (VSV/NL4-3), and infection with native HIV-1/NL4-3 all contained IL-8, but the chemokine expression was increased by VSV/NL4-3 and native HIV-1 exposure. In contrast, IL-6 was only detected after exposure of astrocytes to native HIV-1 (Fig. 6C). To investigate the virus specificity of the IL- 6 response, we exposed HFA to X4 NL4-3; CM235, an R5 HIV-1; or VSV/NL4-3 and then tested the expression of IL-6 by ELISA (Fig. 6D). Both the $\mathrm{X} 4$ and the R5 HIV-1-induced IL-6 protein expression. However the replication competent VSV/NL4-3 (which lacks gp120) failed to induce IL- 6 within the test time frame, strongly suggesting that gp120 binding and no other HIV-1 function was the initiator of the IL-6 response. To determine the kinetics of the observed responses to HIV-1, HFA were mock-infected or infected
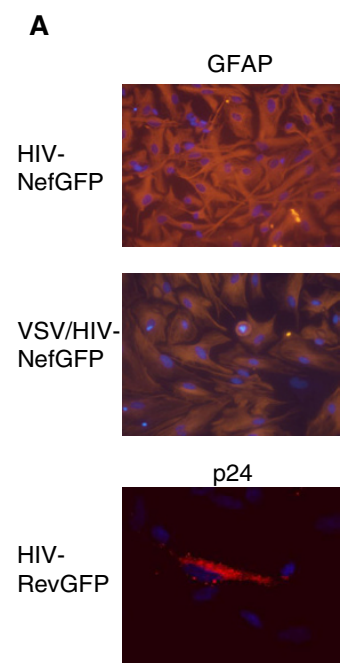

B

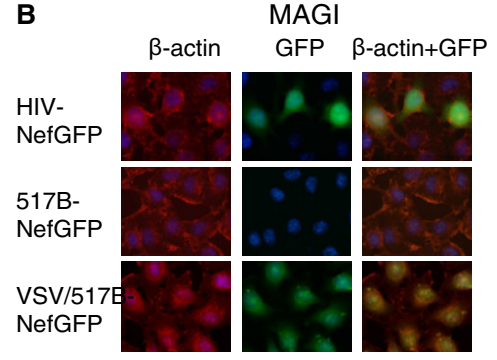

Astrocytes
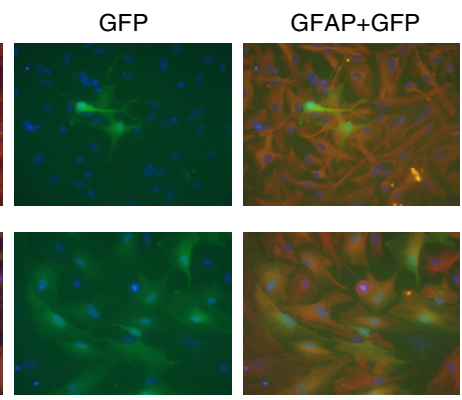

GFP
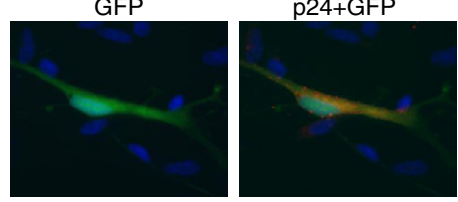

\section{Figure 5}

Expression of HIV-I regulatory and structural genes by infected HFA and control cells. A) HFA were infected with VSV-G pseudotyped NL4-3 encoding a NefGFP fusion protein (first row), with native NL4-3 encoding NefGFP (second row) or encoding RevGFP (third row). Two days after infection HFA were stained using specific antibodies for GFAP (first and second rows) or p24 (third row) and with DAPI and Texas Red-labeled secondary antibodies. Images of red and green fluorescence were superimposed (third column). B) MAGI cells were infected with NL4-3 encoding NefGFP (first row), or fusion incompetent 5 I7B encoding NefGFP (second row), or 5 I7B-NefGFP pseudotyped by VSV-G (third row). Two days after infection cells were stained with anti-actin, DAPI, and Texas Red-labeled secondary antibody and images of red and green fluorescence were superimposed (third column).

by NL4-3 and at time increments between $1 \mathrm{~h}$ and $12 \mathrm{~h}$ cells were harvested for quantitative real-time PCR assay of their levels of IL-6 and IL-8 transcripts (Fig. 6E). The RNA measurements were standardized by the levels of glyceraldehyde phosphate dehydrogenase RNA and data are expressed as fold change relative to cells harvested at 0 time, immediately prior to infection or mock infection (Fig. 6E). Both transcripts were induced rapidly after HIV- 
1 exposure and then declined by 9-12 h. In contrast in mock-infected cells IL- 6 expression was slightly reduced in culture and IL-8 expression increased 15-fold after $3 \mathrm{~h}$ in culture, the latter consistent with the results of multi-protein blots (Fig. 6A-C). Similar results were obtained in at least seven independent experiments utilizing different preparations of astrocytes and different virus batches. These results indicate that the near-universal binding of HIV-1 to HFA results in a rapid induction of expression of two arms of innate immunity, interferon-based and chemokine-based.

\section{Discussion}

The results presented here reveal a new basis for functional responses of astrocytes to HIV-1. We show that effectively all of the cells in cultured fetal astrocyte populations bind HIV-1 but only a small minority of cells permits HIV-1 infection. HIV-1 binding is sufficient to trigger rapid synthesis of IL-6, one of the major innate immune effectors associated with HIV-1 neuropathogenesis [13] and it increases the expression of IL-8, a potent chemokine [81]. These results suggest that HIV-1 affects astrocyte physiology on a cell population-wide basis primarily through binding to cells and binding-induced signaling, rather than infection.
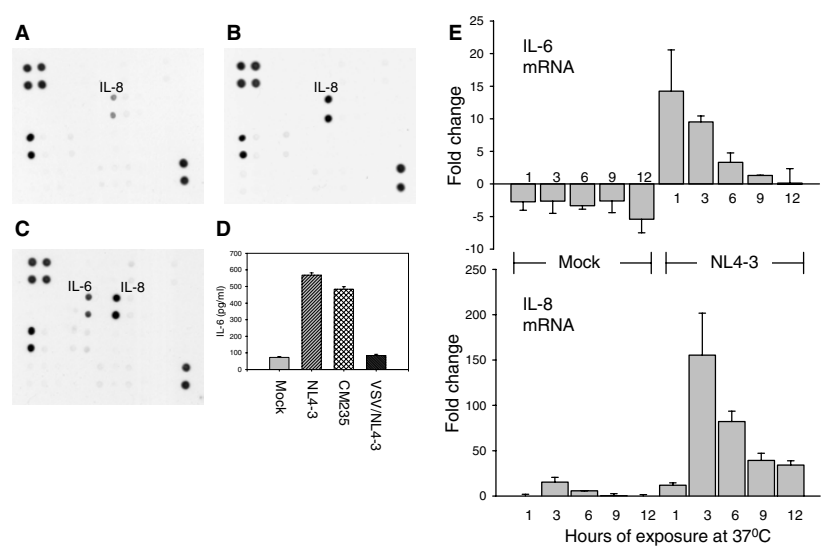

\section{Figure 6}

Induction of cytokines by exposure of HFA to HIV-I. A-C) HFA were mock-infected (panel A); infected with VSV/ NL4-3, a VSV-G pseudotyped NL4-3 incapable of expressing gP I 20 (panel B), or infected with NL4-3 (panel C), washed, and after $24 \mathrm{~h}$ incubation cell supernatants were collected and applied to RayBio Human Cytokine Antibody Array 3.I. The map of antibodies present on the array can be accessed at http://www.raybiotech.com/map/human III map.pdf. D) HFA were infected as indicated, washed, and after $24 \mathrm{~h}$ incubation supernatants were collected for assay of IL- 6 levels by ELISA. E) The expression of IL-6 (upper panel) and IL-8 (lower panel) mRNA by HFA was measured by qPCR at the indicated times after mock infection or NL4-3 infection.
Resolution at the single cell level permitted us to draw these conclusions. We employed a GFP-Vpr tagged "green HIV-1" [72] and infectious HIV-1 expressing Rev- or NefGFP fusion proteins to assess the relative efficiency of virus binding, entry, and expression by fluorescence microscopy. Binding was clearly the most pronounced step of HIV-1 interaction with astrocytes. HIV-1 bound to the majority of astrocytes in our cell cultures, similar to its interaction with CD4-positive cells as visualized by microscopy and exceeding binding to some CD4-positive cells as measured by p24 association (Figs. 1 and 3). The binding observed was specific as indicated in its competition with excess unlabeled virus (Fig. 1) and the absence of binding to unrelated CD4-negative cells (Figs. 2 and 3). The HIV-1 interaction with astrocytes is likely to be mediated by the viral envelope glycoprotein gp120 because preincubation of GFP-Vpr tagged virions with soluble CD4 prevented HIV-1 binding in our study (Fig. 1) and it was shown to block astrocyte infection by HIV-1 in a previous report [61]. Furthering supporting this conclusion, another study demonstrated that recombinant gp120 binds to a single-class binding site on human fetal astrocytes and that the affinity of this interaction approaches that of the gp120-CD4 binding [60]. Taken together, our results directly show that, like human $\mathrm{T}$ lymphocytes and macrophages, human astrocytes can be classified as a cell type fully competent to bind HIV-1. We do not know at present whether adult astrocytes exhibit similar HIV-1 binding characteristics as fetal cells used in the present work, but it should be noted that fetal astrocytes are an acceptable model for study of many receptor-ligand interactions including those with neurotransmitters, cytokines, and growth factors $[57,82,83]$. Given the size of the astroglial compartment [17], our findings raise the possibility that astrocytes present a major target for absorbing HIV-1 and gp120 produced in HIV-1-infected brain.

The cell surface receptor(s) responsible for HIV-1 binding to astrocytes has not been conclusively identified although several candidate proteins have been described $[78,84]$. CD4 serves as the binding receptor for HIV-1 on $\mathrm{T}$ lymphocytes and macrophages and binding to CD4 facilitates binding to co-receptors required for virus-cell fusion [85]. Astrocytes do not express CD4 [60] but have been shown to variously display viral co-receptors including CCR3, CCR5, and CXCR4 [74,75] and in some other systems the viral co-receptor is sufficient to bind immunodeficiency viruses. CD4-independent HIV-2 and SIV have shown to bind and enter T cells through CXCR4 $[86,87]$ and the major receptor for some FIV on T cells appears to be CXCR4 [88]. Nevertheless, monoclonal antibodies that bind CXCR4, CCR3, or CCR5 did not block HIV-1 binding to HFA. Indeed anti-CXCR4 treatment slightly enhanced HIV-1 binding. A more recent study identified the chemokine receptor D6 as a receptor 
on HFA for certain HIV-1 and HIV-2 clones, but NL4-3 that we employed here could not enter HFA via D6 [84]. These results rule out these chemokine receptors as the major receptors for HIV-1/NL4-3 on HFA but leave open the identity of the receptor.

Compared to T lymphocytes and macrophages, astrocytes undergo only limited infection with HIV-1 in vitro and in vivo $[7,27,28,63,64]$. Explanations advanced by our laboratory and others include inefficient virus entry [65-67] and intracellular restrictions to HIV-1 expression $[63,89]$. This work further clarifies the relative contributions of these mechanisms. By analysis at the single cell level we show that the majority of astrocytes in our cell populations are refractory to HIV-1 infection despite universal binding of virus to HFA (Figs. 1 and 5). We attribute this disparity to inefficient virus entry into the majority of astrocytes that bind HIV-1. The block at entry was indicated by i) different dynamics of HIV-GFP association with HFA and CD4-positive cells at $37^{\circ} \mathrm{C}$ as visualized by fluorescence imaging; ii) the similarity between GFP-Vpr tagged NL4-3 and entry-defective 517B viruses in their respective target cell associations by the same method; and iii) the demonstration at a single cell level that circumventing restricted HIV-1 entry by use of VSV-G pseudotyped virus permits efficient infection of HFA, as also shown by cell population analyses in our previous studies $[33,34,66]$ and consistent with other reports $[34,67,84,90]$. The $517 \mathrm{~B}$ construct of HIV-1 contains a mutation in the fusion domain of gp41 that incapacitates virus-cell fusion and virus entry [77]. Based on analogy with 517B revealed here, HIV-1 binding to HFA may not generally be followed by virus-cell fusion, resulting in inefficient entry in most of the cells exposed to the virus. The mechanism of HIV-1 entry into the minority of HFA that permit virus infection is also uncertain at present, although at least one study suggested it is by endocytosis mediated by a mannose receptor [78].

Although GFP-Vpr tagged HIV-1 is a useful tool to investigate initial virus-cell interactions it is not suitable for enumerating the fraction of astrocyte that does permit virus infection because it does not encode GFP. We used for that purpose infectious HIV-1 expressing RevGFP and NefGFP fusion proteins. Other investigators have also employed RevGFP constructs to investigate its function on astrocytes outside HIV-1 infection [91]. RevGFP and NefGFP are not subject to the proposed intracellular restrictions to HIV-1 replication in astrocytes $[63,89]$ and thus their detection accurately marks all HFA in our cell populations that allow virus entry and expression. We found that Rev and Nef were expressed only in a small fraction of cells, about $1 \%$ (Fig. 5), consistent with previous reports $[68,69]$. Of note, the HIV-RevGFP-infected astrocytes also expressed p24 in double-label analysis (Fig. 5).
This indicates that some astrocytes may permit completion of the HIV-1 replicative cycle, at least during acute infection and consistent with our studies with VSV-G/HIV and some other reports $[33,66,67,84,90]$. However, our studies do not exclude the possibility that following transition to chronic infection astrocytes may impose some restrictions on HIV-1 expression, as indicated by establishment of inducible HIV-1 latency in chronically infected HFA in vitro [92] and limited HIV-1 expression by infected cells in vivo [7]. Regardless of the mechanism of long-term HIV-1 infection in astrocytes, our work makes clear that only a small fraction of HFA competent to bind HIV-1 is susceptible to HIV-1 entry and expression at any given time. It is unknown at present whether HIV-1 infects cells randomly or it targets some yet undefined astrocyte subpopulation $[18,19]$. More research is needed to identify HIV-1 susceptible cells in order to understand the pathogenic potential of this infection.

In addition, binding of HIV-1 through gp120 has functional consequences for HFA as previously reported $[54,55]$ and as shown here. Our results demonstrate that HFA can be triggered to IL- 6 expression by HIV-1 binding but that HIV-1 infection by VSV-G/pseudotyped, gp120negative virus capable of expressing all other viral genes cannot trigger this gene expression. These findings indicate that gp120 binding and no other viral function activated IL- 6 expression, at least in this $24 \mathrm{~h}$ exposure period. Indeed, the induction of the IL- 6 transcript was maximal at the first time point tested, $1 \mathrm{~h}$ after virus exposure. IL- 8 induction peaked somewhat later, at $3 \mathrm{~h}$ after exposure. Previous studies have shown that HIV-1 Tat can activate astrocytes to IL-8 production, although the activation was about 10-fold less than that observed here [44]. Because we find a small minority of cells susceptible to HIV-1 infection, it is more likely that the IL- 8 expression observed here resulted from gp120 binding to HFA than from virus replication and Tat production. IL-8 is a major chemotactic factor for a variety of leukocytes [81] and increased IL-6 in the central nervous system has been associated with brain disease in SIV-infected macaques and has been implicated as a critical controlling element in brain disease in the SIV-macaque model $[13,93]$. Our observation raises the possibility that exposure of astrocytes in the brain to HIV-1 or to gp120 is responsible for the observed increase in this key antiviral cytokine, independently of virus replication in the brain. If the results reported here faithfully reproduce the behavior of astrocytes in the brain, then this numerous and essential brain cell type is exquisitely responsive to HIV-1 and its responses may be a major factor in HIV-1 neuropathogenesis. 


\section{Conclusion}

Our results indicate that HIV-1 binding to human astrocytes, although extensive, is not generally followed by virus entry and replication. Astrocytes respond to HIV-1 binding by rapidly increased cytokine production suggesting a role of this virus-brain cell interaction in HIV-1 neuropathogenesis.

\section{Methods}

\section{Plasmid construction}

pEGFP-Vpr plasmid was obtained from Dr. T. Hope (Northwestern University). To generate the vector encoding infectious NL4-3 expressing NefGFP, the wild-type HIV-1 pNL4-3 vector (from NIH AIDS Research and Reference Reagent Program, Germantown, MD) was PCR amplified using the Pfu DNA polymerase (Stratagene, La Jolla, CA) with primer pair 5'-CGATTAGTGAACGGATCCTTAG-3' and 5'-CTTGCTCACCATAGCGGCCGCCCACTTGCCACCCATCTTATA-3'; pGFP-C1 was PCR amplified with primer pair 5'-ATGGGTGGCAAGTGGGCGGCCGCTATGGTGAGCAAGGGCGAG-3' and 5'GACGTCGCTCGAGTTACTTGTACAGCTCGTCC-3'. The PCR products were run and separated on $1 \%$ agarose gel, purified by Ultrafree-DA tubes (Millipore, Billerica, MA), then used as template for PCR with primer pair 5'-CGATTAGTGAACGGATCCTTAG-3' and 5'-GACGTCGCTCGAGTTACTTGTACAGCTCGTCC-3'. The second round PCR product which joined above two fragments (HIV-1 and GFP coding sequence) was ligated to Bam H I and Xho I sites of pNL4-3 plasmid. To generate vector HIV/ RevGFP, HIV-1/Lai (from NIH AIDS Research and Reference Reagent Program) was PCR amplified using the Pfu DNA polymerase with primer pair 5'-CGATTAGTGAACGGATCCTTAG-3' and 5'-CTCGCCCTTGCTCACCATTTCTTTAGTTCCTGACTCCAA-3'; pGFP-C1 was PCR amplified with primer pair 5'-TCAGGAACTAAAGAAATGGTGAGCAAGGGCGAGGAGCTG-3' and 5'-GACGTCGCTCGAGTTACTTGTACAGCTCGTCC-3'. The PCR products were run and separated on $1 \%$ agarose gel, purified by Ultrafree-DA tubes (Millipore), then used as template for PCR with primer pair 5'-CGATTAGTGAACGGATCCTTAG-3' and 5'-GACGTCGCTCGAGTTACTTGTACAGCTCGTCC-3'. The second round PCR product which jointed above two fragments was ligated to BamH I and Xho I sites of pHIV-1/Lai plasmid. The construction of all of the above plasmids were confirmed by restriction enzyme digestion or sequencing. The NL4-3-517B was constructed by excising the envelope coding sequence from pHXB2-517B [77], obtained from Dr. J. Sodroski, Harvard Medical School, and inserting it into the Sal I and BamH I sites of pNL4-3. Plasmid encoding infectious CM235 [94] was kindly provided by Dr. P. Ehrenberg (Walter Reed Army Institute of Research, Rockville, MD).

\section{Cell culture, transfection and infection}

HFA were isolated from second trimester human fetal brains (gestational age 16-19 weeks) obtained from elective abortions in full compliance with National Institutes of Health guidelines. Highly enriched HFA preparations were obtained by high-density culture in the absence of growth factors in F12 DMEM (Invitrogen, Carlsbard, CA) containing 10\% fetal bovine serum (FBS) and antibiotics essentially as described [66]. The cells were propagated in the same medium at $2-5 \times 10^{4}$ cells $/ \mathrm{cm}^{2}$ and subcultured weekly up to 4 times. Experiments were performed on HFA in passage 3 ; at this stage $>99 \%$ of cells stained positive for the astrocyte marker GFAP and no microglial contamination was detectable by anti-CD68 staining (not shown; $[33,66])$. 293T, HeLa and HeLa-CD4-LTR- $\beta$ Gal (MAGI) cells were obtained from the NIH AIDS Research and Reference Reagent Program; the cells were cultured in DMEM supplemented with $10 \%$ FBS and penicillin-streptomycin $(100 \mathrm{U} / \mathrm{ml})$. Transfections were performed by the standard calcium phosphate precipitation method which usually in our hands has over $50 \%$ transfection efficiency in 293 T cells. PBL from healthy donors were activated for $48 \mathrm{~h}$ with phytohemagglutinin (PHA) and were then cultivated in RPMI 1640 medium supplemented with $10 \%$ FBS. CEM cells were cultured in RPMI-1640 containing $10 \%$ FBS.

\section{Concentration and purification of viral particles}

To prepare HIV-GFP 293T cells were cotransfected with an EGFP-Vpr and a designated HIV-1 plasmid and after two days supernatant was collected and virus content determined using the HIV-1 Ag ELISA kit, Coulter, Hialeah, FL. Alternatively, PBL were infected with different strains of HIV-1, after 5 days, supernatant was collected, filtered through $0.22-\mu \mathrm{m}$-pore-size filters, layered over a $20 \%$ sucrose cushion in PBS, and centrifuged for $1 \mathrm{~h}$ at 20,000 $\times g$. The viral pellet was washed once, resuspended in PBS, and virus content was determined by p24 ELISA.

\section{Determination of virus binding by measurement of cell- associated $p 24$}

HFA, CD4-negative 293T or HeLa, and CD4-positiveMAGI cells $\left(2 \times 10^{5}\right.$ cells/well in 12 -well plates $)$ were incubated with indicated virus preparations at a dose of $1 \mathrm{pg}$ p24 per cell for $2 \mathrm{~h}$ at $4{ }^{\circ} \mathrm{C}$. This dose is equivalent to one infectious unit (I.U.) per cell as determined by virus infectivity assay in MAGI cells [73]. To evaluate inhibition of virus binding, cells were exposed to human anti-CXCR4 (12G5), anti-CCR5 (5C7) or anti-CCR3 (7B11) monoclonal antibodies (NIH AIDS Research and Reference Reagent Program) at $1 \mu \mathrm{g} / \mathrm{ml}$ for $30 \mathrm{~min}$ prior to virus exposure at either $37^{\circ} \mathrm{C}$ or $4^{\circ} \mathrm{C}$ in a final volume of 500 $\mu \mathrm{l}$ and then exposed to virus for $1 \mathrm{~h}$ at $4^{\circ} \mathrm{C}$. At the end of the incubation period, cells were vigorously washed five times with PBS to remove unabsorbed virus and lysed 
with $300 \mu \mathrm{l}$ of PBS containing $0.5 \%$ NP40. The lysates were cleared by centrifugation $(10,000 \times g$ for $5 \mathrm{~min})$ and the p24 content of the lysate was determined by ELISA. The percentage of virus particles bound by cells was calculated by the following formula: [(pg p24 associated with cells $) /(p g$ input p24) $\times 100]$. All virus binding or infection assays were performed in duplicate or triplicate.

\section{Determination of GFP-Vpr virus binding and entry by fluorescence microscopy and image analysis}

For binding experiments, HFA, HeLa and MAGI cells were grown in 12-well plates with round coverslips. Cells were exposed to HIV-GFP virions at $1 \mathrm{pg}$ viral p24 per cell for 1 $\mathrm{h}$ at $4{ }^{\circ} \mathrm{C}$. To compete for HIV-GFP binding, cells were exposed to 10-fold excess of unlabeled NL4-3 virions for $1 \mathrm{~h}$ at $4^{\circ} \mathrm{C}$ prior to exposure to HIV-GFP virions. To inhibit binding, HIV-GFP virions were pretreated with 20 $\mu \mathrm{g} / \mathrm{ml}$ of soluble CD4 prior to incubation with cells. Virus-cell mixtures were then washed five times with PBS to remove unabsorbed virus; washed cells were fixed with $2 \%$ paraformaldehyde in PBS, stained with $1 \mathrm{ng} / \mathrm{ml}$ of DAPI in methanol for detection of nuclei, stained with primary antibodies, washed, stained with Texas Red linked cognate secondary antibodies (Amersham, Piscataway, NJ), washed, air dried, and mounted in glass slides with $50 \%$ glycerol in PBS. To follow virus internalization, cells were exposed to HIV-GFP virions at $4^{\circ} \mathrm{C}$ for $1 \mathrm{~h}$, washed, supplemented with appropriate media, cultured $37^{\circ} \mathrm{C}$ for the designated periods of time, and fixed and observed or stained as described above. Fluorescence images were captured by using a digital video imaging microscope system consisting of a Zeiss Model Axioplan 2 microscope (Carl Zeiss, Thornwood, NY) with a HAMAMATSU ORCA-ER digital camera (HAMAMATSU Corp, Bridgewater, NJ) and Openlab software (Improvision, Lexington, MA).

\section{Human cytokine array}

HFA were mock infected or incubated with designated virus for $5 \mathrm{~h}$ at $37^{\circ} \mathrm{C}$, cells were washed five times and cultured in low serum medium overnight. Supernatant were collected and incubated with the Human Cytokine Array 3.1 multiprotein blot (Ray Biotech, Norcross, GA) membrane for $2 \mathrm{~h}$ at room temperature. After decanting the samples from container, the membrane was washed three times. Biotinylated anti-human cytokine antibodies were added and incubated at room temperature for $2 \mathrm{~h}$. This was followed by washing, incubation with streptavidin conjugated peroxidase, and visualization by enhanced chemiluminescence system (Amersham).

\section{Quantitative real-time RT-PCR (qPCR)}

HFA were mock-infected or infected with 1 pg p24 per cell of NL4-3, and RNA was extracted and cDNA was synthesized as described above. qPCR was conducted as described [95] using Taqman chemistry with human IL-6, IL-8, and GAPDH probes and primers designed using Primer Express v.1.0 (Applied Biosystems). PCR reaction contained $5 \mu \mathrm{l}$ of ABI $2 \times$ Universal Master Mix, $1.25 \mu \mathrm{l}$ of each forward and reverse primers at 200-900 nM, $1 \mu \mathrm{l}$ of probe at 50-200 nM, and RNAase/DNAase free water. All reactions were performed in duplicate and were run in an ABI 7500. Raw data were analyzed using the Sequence Detection Software (ABI); relative quantitation employed the comparative threshold cycle method (Applied Biosystems Technical Bulletin \#2). Signals were normalized to signals of the levels of GAPDH transcripts and are presented as fold changes versus 0 time, with cells collected before infection or mock infection.

\section{IL-6 ELISA}

The IL-6 protein level in cell growth medium was detected by human IL-6 ELISA development system (R\&D Systems Inc, Minneapolis, MN). Briefly, 96-well plates were coated with anti-human IL- 6 monoclonal antibodies overnight, samples were added to the designated wells with $100 \mu \mathrm{l}$ per well and incubated at RT for $2 \mathrm{~h}$. Fluid was aspirated and the wells were washed three times with washing buffer. Then $100 \mu$ l biotinylated anti-human IL-6 was added to each well and incubated at RT for $2 \mathrm{~h}$. This was followed by washing, incubation with streptavidin conjugated peroxidase and color development.

\section{Antibodies and other reagents}

Anti-capsid (HIV-1 p24) monoclonal antibody was obtained from the NIH AIDS Research and Reference Reagent Program. Anti- $\beta$-actin monoclonal antibody was purchased from Sigma (St. Louis, MO). Anti-GFAP polyclonal antibodies were purchased from DAKO Corporation (Carpinteria, CA).

\section{Abbreviations}

HIV-1: human immunodeficiency virus type 1: HFA: human fetal astrocytes; HAD: HIV-associated dementia; GFP: green fluorescence protein

\section{Authors' contributions}

Jinliang Li designed experiments, conducted most of the work, and wrote draft of the manuscript; Galina Bentsman established, maintained, and characterized cultures of human fetal astrocytes and conducted some of the analytical assays; Mary Jane Potash conducted critical data analysis and interpretation and co-wrote the manuscript; David Volsky planned, designed, and supervised the work, analyzed data, and co-wrote the manuscript.

\section{Acknowledgements}

The authors thank Dr. P. Ehrenberg for providing CM235 plasmid DNA, Dr. J. Sodroski for providing 5I7B plasmid DNA, and Dr. T. Hope for providing the GFP-Vpr vector. Ms. I. M. Totillo for manuscript preparation. The following reagents were provided through the AIDS Research and Refer- 
ence Reagent Program, DAIDS, NIAID, NIH: pLai from Dr. K. Peden, pNL4-3 from Dr. M. Martin, anti-p24 monoclonal antibody from Dr. B. Chesebro and Dr. K. Wehrly, and recombinant soluble CD4 from Progenics Pharmaceuticals, Inc. This work was supported by grants NS3 I492, DA017618, NS054580, and NS39191 from the National Institutes of Health, Public Health Service.

\section{References}

I. Navia AD, Price WR: Clinical and biologic features of the AIDS dementia complex. In The Neurology of AIDS Edited by: Gendelman HE, Lipton AS, Epstein L and Swindells S. New York, Chapman \& Hall; 1998:229-240.

2. Everall I, Luthert P, Lantos P: A review of neuronal damage in human immunodeficiency virus infection: its assessment, possible mechanism and relationship to dementia. J Neuropathol Exp Neurol 1993, 52:56 I-566.

3. Masliah E, Ge N, Achim CL, Hansen LA, Wiley CA: Selective neuronal vulnerability in HIV encephalitis. J Neuropathol Exp Neurol | 992, 5 |:585-593.

4. Everall IP, Hudson L, AI-Sarraj S, Honavar M, Lantos P, Kerwin R: Decreased expression of AMPA receptor messenger RNA and protein in AIDS: A model for HIV-associated neurotoxicity. Nat Med 1995, I: I I74-I I78.

5. Torres-Muñoz J, Stockton P, Tacoronte N, Roberts B, Maronpot RR, Petito CK: Detection of HIV-I gene sequences in hippocampal neurons isolated from postmortem AIDS brains by laser capture microdissection. J Neuropath Exp Neur 200I, 60:885-892.

6. Wiley CA, Schrier RD, Nelson JA, Lampert PW, Oldstone MBA: CelIular localization of human immunodeficiency virus infection within the brains of acquired immune deficiency syndrome patients. Proc Natl Acad Sci USA 1986, 83:7089-7093.

7. Takahashi K, Wesselingh SL, Griffin DE, McArthur JC, Johnson RT, Glass JD: Localization of HIV-I in human brain using polymerase chain reaction/in situ hybridization and immunocytochemistry. Ann Neurol 1996, 39:705-7II.

8. Lipton S, Gendelman HE: Dementia associated with the acquired immunodeficiency syndrome. New Engl J Med 1995 233:934-940.

9. González-Scarano F, Martín-García J: The neuropathogenesis of AIDS. Nat Rev Immunol 2005, 5:69-8I.

10. Achim CL, Wiley CA: Inflammation in AIDS and the role of the macrophage in brain pathology. Curr Opin Neurol 1996, 9:221-225.

II. Kaul M, Garden GA, Lipton SA: Pathways to neuronal injury and apoptosis in HIV-associated dementia. Nature 200I, 41 0:988-994.

12. Genis P, Jett M, Bernton EW, Boyle T, Gelbard HA, Dzenko K, Keane RW, Resnick L, Mizrachi Y, Volsky DJ, Epstein LG, Gendelman HE: Cytokines and arachidonic metabolites produced during human immunodeficiency virus (HIV)-infected macrophageastroglia interactions: implications for the neuropathogenesis of HIV disease. J Exp Med 1992, I76:1703-I718.

13. Barber SA, Herbst DS, Bullock BT, Gama L, Clements JE: Innate immune responses and control of acute simian immunodeficiency virus replication in the central nervous system. J NeuroVirol 2004, I 0 (suppl. I): I 5-20

14. Zink MC, Coleman GD, Mankowski JL, Adams RJ, Tarwater PM, Fox $\mathrm{K}$, Clements JE: Increased macrophage chemoattractant protein-I in cerebrospinal fluid precedes and predicts simian immunodeficiency virus encephalitis. J Infect Dis 200I, 184:1015-1021.

15. Gelbard HA, Nottet HSLM, Swindells S, Jett M, Dzenko KA, Genis P White R, Wang L, Choi YB, Zhang D, Lipton SA, Tourtellotte WW Epstein LG, Gendelman HE: Platelet-activating factor: a candidate human immunodeficiency virus type $\mathbf{I}$-induced neurotoxin. J Virol 1994, 68:4628-4635.

16. Wesselingh SL, Takahashi K, Glass DJ, McArthur JC, Griffin JW, Griffin DE: Cellular localization of tumor necrosis factor mRNA in neurological tissue from HIV-infected patients by combined reverse transcriptase/polymerase chain reaction in situ hybridization and immunohistochemistry. J Neuroimmunol 1997, 74:1-8.

17. Schubert D: Developmental Biology of Cultured Nerve, Muscle, and Glia. New York, Wiley and Sons; 1984.
18. Bachoo RM, Kim RS, Ligon KL, Maher EA, Brennan C, Billings N, Chan S, Li C, Rowitch DH, Wong WH, DePinho RA: Molecular diversity of astrocytes with implications for neurological disorders. Proc Natl Acad Sci USA 2004, I 0 I:8384-8389.

19. Davies DL, Niesman IR, Boop FA, Phelan KD: Heterogeneity of astroglia cultured from adult human temporal lobe. Int J Dev Neurosci 2000, I8: I5I-160.

20. Danbolt NC: Glutamate uptake. Prog Neurobiol 200 I, 65: I- 105.

2I. Benveniste EN, Shrikant P, Patton HK, Benos DJ: Neuroimmunologic mechanisms for disease in AIDS: The role of the astrocyte. In The Neurology of AIDS Edited by: Gendelman HE, Lipton AS, Epstein L and Swindells S. New York, Chapman \& Hall; 1998: 130-146.

22. Fields RD, Stevens-Graham B: New insights into neuron-glia communication. Science 2002, 298:556-562.

23. Bezzi $P$, Volterra A: A neuron-glia signalling network in the active brain. Curr Opin Neurobiol 200 I, I I:387-394.

24. Sharer LR, Epstein LG, Cho ES, Joshi VV, Meyenhofer MF, Rankin LF, Petito CK: Pathologic features of AIDS encephalopathy in children: evidence for LAV/HTLV-III infection of brain. Hum Pathol 1986, I 7:27|-284.

25. Budka H: Neuropathology of human immunodeficiency virus infection. Brain Pathol 1991, I:163-175.

26. An SF, Groves M, Giometto B, Beckett AAJ, Scaravilli F: Detection and localisation of HIV-I DNA and RNA in fixed adult AIDS brain by polymerase chain reaction/in situ hybridisation technique. Acta Neuropathol 1999, 98:48I-487.

27. Saito Y, Sharer LR, Epstein LG, Michaels J, Mintz M, Louder M, Golding $K$, Cvetkovich TA, Blumberg BM: Overexpression of nef as a marker for restricted HIV-I infection of astrocytes in postmortem pediatric central nervous tissues. Neurology 1994, 44:474-48I

28. Tornatore C, Chandra R, Berger JR, Major EO: HIV-I infection of subcortical astrocytes in the pediatric central nervous system. Neurology 1994, 44:48I-487.

29. Ranki A, Nyberg M, Ovod V, Haltia M, Elovaara I, Raininko R, Haapasolo H, Krohn K: Abundant expression of HIV Nef and Rev proteins in brain astrocytes in vivo is associated with dementia. AIDS 1995, 9:100I-1008.

30. Trillo-Pazos G, Diamanturos A, Rislove L, Menza T, Chao W, Belem P, Sadiq S, Morgello S, Sharer L, Volsky DJ: Detection of HIV-I DNA in microglia/macrophages, astrocytes and neurons isolated from brain tissue with HIV-I encephalitis by laser capture microdissection. Brain Pathol 2003, I 3: | 44-I 54.

31. Shi B, De Girolami U, He J, Wang S, Lorenzo A, Busciglio J, Gabuzda D: Apoptosis induced by HIV-I infection of the central nervous system. J Clin Invest 1996, 98:1979-1990.

32. Thompson KA, McArthur JC, Wesselingh SL: Correlation between neurological progression and astrocyte apoptosis in HIVassociated dementia. Ann Neurol 2001, 49:745-752.

33. Kim SY, Li J, Bentsman G, Brooks Al, Volsky DJ: Microarray analysis of changes in cellular gene expression induced by productive infection of primary human astrocytes: implications for HAD. J Neuroimmunol 2004, I 57:17-26.

34. Cosenza-Nashat MA, Si Q, Zhao ML, Lee SC: Modulation of astrocyte proliferation by HIV-I: Differential effects in productively infected, uninfected, and Nef-expressing cells. J Neuroimmunol 2006, I 78:87-99.

35. Dou H, Morehead J, Bradley J, Gorantla S, Ellison B, Kingsley J, Smith LM, Chao W, Bentsman G, Volsky DJ, Gendelman HE: Neuropathologic and neuroinflammatory activities of HIV-I-infected human astrocytes in murine brain. Glia 2006, 54:8I-93.

36. Brack-Werner R: Astrocytes: HIV cellular reservoirs and important participants in neuropathogenesis. AIDS 1999, 13:1-22.

37. Conant K, Major EO: Astrocytes as mediators of CNS injury in AIDS. In The Neurology of AIDS Edited by: Gendelman HE, Lipton AS, Epstein L and Swindells S. New York, Chapman \& Hall; 1998: 147- 155.

38. Wang Z, Trillo-Pazos G, Kim SY, Canki M, Morgello S, Sharer LR, Gelbard HA, Su ZZ, Kang DC, Brooks AI, Fisher PB, Volsky DJ: Effects of human immunodeficiency virus type $I$ on astrocyte gene expression and function: Potential role in neuropathogenesis. J NeuroVirol 2004, 10:25-32.

39. Lavi E, Kolson LD, Ulrich MA, Fu L, González-Scarano F: Chemokine receptors in the human brain and their relationship to HIV infection. J NeuroVirol I998, 4:30I-3II. 
40. Glabinski AR, Ransohoff RM: Chemokines and chemokine receptors in CNS pathology. J Neurovirol 1999, 5:3-12.

4I. Hesselgesser J, Horuk R: Chemokine and chemokine receptor expression in the central nervous system. J Neurovirol 1999 , 5:13-26.

42. Conant K, Garzino-Demo A, Nath A, McArthur JC, Halliday W Power C, Gallo RC, Major EO: Induction of monocyte chemoattractant protein-I in HIV-I Tat-stimulated astrocytes and elevation in AIDS. Proc Natl Acad Sci USA 1998, 95:31 I7-3121.

43. Cota M, Kleinschmidt A, Ceccherini-Silberstein F, Aloisi F, Mengozzi M, Mantovani A, Brack-Werner R, Poli G: Upregulated expression of interleukin-8, RANTES, and chemokine receptors in human astrocytic cells infected with HIV-I. J Neurovirol 2000 , 6:75-83.

44. Kutsch O, Oh JW, Nath A, Benveniste EN: Induction of the chemokines interleukin-8 and IP-I 0 by human immunodeficiency virus type I Tat in astrocytes. J Virol 2000, 74:92|4-922I.

45. McManus CM, Weidenheim K, Woodman SE, Nunez J, Hesselgesser J, Nath A, Berman JW: Chemokine and chemokine-receptor expression in human glial elements: induction by the HIV protein, Tat, and chemokine autoregulation. Am J Pathol 2000 I 56: |44|-|453.

46. Ronaldson PT, Bendayan R: HIV-I viral envelope glycoprotein gp 120 triggers an inflammatory response in cultured rat astrocytes and regulates the functional expression of P-glycoprotein. Mol Pharmacol 2006, 70:1087-1098.

47. Liu X, Jana M, Dasgupta S, Koka S, He J, Wood C, Pahan K: Human immunodeficiency virus type I (HIV-I) tat induces nitric oxide synthase in human astroglia. I Biol Chem 2002, 277:39312-39319

48. El-Hage N, Gurwell JA, Singh IN, Knapp PE, Nath A, Hauser KF: Synergistic increases in intracellular $\mathrm{Ca2+}$, and the release of MCP-I, RANTES, and IL-6 by astrocytes treated with opiates and HIV-I Tat. Glia 2005, 50:91-106.

49. El-Hage N, Wu G, Wang J, Ambati J, Knapp PE, Reed JL, Bruce-Keller A], Hauser KF: HIV-I Tat and opiate-induced changes in astrocytes promote chemotaxis of microglia through the expression of MCP-I and alternative chemokines. Glia 2006, 53: $132-146$

50. Yeung MC, Pulliam L, Lau AS: The HIV envelope protein gp I 20 is toxic to human brain-cell cultures through the induction of interleukin-6 and tumor necrosis factor-alpha. AIDS 1995, 9:| $37-143$.

5I. Su Z, Kang D, Chen Y, Pekarskaya O, Chao W, Volsky DJ, Fisher PB: Identification and cloning of human astrocyte genes displaying elevated expression after infection with HIV-I or exposure to HIV-I envelope glycoprotein by rapid subtraction hybridization, RaSH. Oncogene 2002, 2 I:3592-3602.

52. Su ZZ, Kang D, Chen Y, Pekarskaya O, Chao W, Volsky DJ, Fisher PB: Identification of gene products suppressed by human immunodeficiency virus type I infection or gp I 20 exposure of primary human astrocytes by rapid subtraction hybridization. NeuroVirol 2003, 9:372-389.

53. Galey D, Becker K, Haughey N, Kalehua A, Taub D, Woodward J, Mattson $M$, Nath A: Differential transcriptional regulation by human immunodeficiency virus type I and gp I 20 in human astrocytes. J NeuroVirol 2003, 9:358-37I.

54. Benos DJ, Hahn BH, Bubien JK, Ghosh SK, Mashburn NA, Chaikin MA, Shaw GM, Benveniste EN: Envelope glycoprotein gp I 20 of human immunodeficiency virus type I alters ion transport in astrocytes: implications for AIDS dementia complex. Proc Natl Acad Sci USA 1994, 9 I:494-498.

55. Wang Z, Pekarskaya O, Bencheikh M, Chao W, Gelbard H, Ghorpade A, Rothstein JD, Volsky DJ: Reduced expression of glutamate transporter EAAT2 and impaired glutamate transport in human primary astrocytes exposed to HIV-I or gp I 20. Virology 2003, 3 I 2:60-73.

56. Zhou BY, Liu Y, Kim B, Xiao Y, He J]: Astrocyte activation and dysfunction and neuron death by HIV-I Tat expression in astrocytes. Mol Cell Neurosci 2004, 27:296-305.

57. Fine SM, Angel RA, Perry SW, Epstein LG, Rothstein JD, Dewhurst S, Gelbard HA: Tumor necrosis factor a inhibits glutamate uptake by primary human astrocytes. J Biol Chem 1996, 27 I: I5303-I5306.

58. Holden CP, Haughey NJ, Nath A, Geiger JD: Role of $\mathbf{N a + / H +}$ exchangers, excitatory amino acid receptors and voltage- operated $\mathrm{Ca} 2+$ channels in human immunodeficiency virus type I gp I20-mediated increases in intracellular $\mathrm{Ca2+}$ in human neurons and astrocytes. Neuroscience 1999. 91:1369-1378.

59. Bezzi P, Domercq M, Brambilla L, Galli R, Schols D, De Clercq E, Vescovi A, Bagetta G, Kollias G, Meldolesi J, Volterra A: CXCR4-activated astrocyte glutamate release via TNFa: amplification by microglia triggers neurotoxicity. Nat Neurosci 2001, 4:702-710.

60. Ma M, Geiger JD, Nath A: Characterization of a novel binding site for the human immunodeficiency virus type I envelope protein gpl20 on human fetal astrocytes. I Virol 1994, 68:6824-6828.

61. Hao HN, Lyman WD: HIV infection of fetal human astrocytes: the potential role of a receptor-mediated endocytic pathway. Brain Res 1999, 823:24-32.

62. Cheng-Mayer C, Rutka JE, Rosenblum ML, McHugh T, Stites DP, Levy IA: Human immunodeficiency virus can productively infect cultured human glial cells. Proc Natl Acad Sci USA 1987, 84:3526-3530.

63. Tornatore C, Nath A, Amemiya K, Major EO: Persistent human immunodeficiency virus type I infection in human fetal glial cells reactivated by $\mathrm{T}$-cell factor(s) or by the cytokines tumor necrosis factor alpha and interleukin-I beta. J Virol 1991, 65:6094-6100.

64. Kunsch C, Hartle HT, Wigdahl B: Infection of human fetal dorsal root ganglion glial cells with human immunodeficiency virus type $I$ involves an entry mechanism independent of the CD4 T4A epitope. J Virol 1989, 63:5054-506I.

65. Schweighardt B, Atwood WJ: HIV type I infection of human astrocytes is restricted by inefficient viral entry. AIDS Res Hum Retroviruses 2001, I 7: I |33-| | 42

66. Canki M, Thai JNF, Chao W, Ghorpade A, Potash MJ, Volsky DJ: Highly productive infection with pseudotyped human immunodeficiency virus type I (HIV-I) indicates no intracellular restrictions to HIV-I replication in primary human astrocytes. J Virol 200I, 75:7925-7933.

67. Willey SJ, Reeves JD, Hudson R, Miyake K, Dejucq N, Schols D, De Clercq E, Bell J, McKnight A, Clapham PR: Identification of a subset of human immunodeficiency virus type I (HIV-I), HIV-2, and simian immunodeficiency virus strains able to exploit an alternative coreceptor on untransformed human brain and lymphoid cells. J Virol 2003, 77:6I38-6I52.

68. He J, Chen Y, Farzan M, Choe H, Ohagen A, Gartner S, Busciglio J, Yang X, Hofmann W, Newman W, Mackay RC, Sodroski J, Gabuzda D: CCR3 and CCR5 are co-receptors for HIV-I infection of microglia. Nature 1997, 385:645-649.

69. Bencheikh M, Bentsman G, Sarkissian N, Canki M, Volsky DJ: Replication of different clones of human immunodeficiency virus type I in primary fetal human astrocytes: enhancement of viral gene expression by Nef. I NeuroVirol 1999, 5: I I5-124.

70. Ludwig E, Ceccherini-Silberstein F, van Empel J, Erfle V, Neumann M, Brack-Werner R: Diminished Rev-mediated stimulation of human immunodeficiency virus type $I$ is a hallmark of human astrocytes. J Virol 1999, 73:8279-8289.

7I. Wang X, Pekarskaya O, Bencheikh M, Canki M, Gelbard H, Ghoparde A, Gendelman HE, Rothstein JD, Volsky DJ: HIV-I infection impairs uptake of the neurotransmitter L-glutamate by primary human astrocytes in vitro. J Virol 1999:Manuscript in preparation..

72. McDonald D, Vodicka MA, Lucero G, Svitkina TM, Borisy GG, Emerman $M$, Hope T]: Visualization of the intracellular behavior of HIV in living cells. J Cell Biol 2002, I 59:44 I-452.

73. Kimpton J, Emerman $M$ : Detection of replication-competent and pseudotyped human immunodeficiency virus with a sensitive cell line on the basis of activation of an integrated bgalactosidase gene. J Virol 1992, 66:2232-2239.

74. Klein RS, Williams KC, Alvarez-Hernandez X, Westmoreland S, Force T, Lackner AA, Luster AD: Chemokine receptor expression and signaling in macaque and human fetal neurons and astrocytes: implications for the neuropathogenesis of AIDS. J Immunol 1999, 163: I636-1646.

75. Boutet A, Salim H, Taoufik Y, Lledo PM, Vincent JD, Delfraissy JF, Tardieu $M$ : Isolated human astrocytes are not susceptible to infection by $M$ - and T-tropic HIV-I strains despite functional 
expression of the chemokine receptors CCR5 and CXCR4. Glia 200I, 34:165-I77.

76. Dimitrov DS, Blumenthal R: Photoinactivation and kinetics of membrane fusion mediated by the human immunodeficiency virus type I envelope glycoprotein. J Virol 1994, 68:1956-1961.

77. Kowalski M, Bergeron L, Dorfman T, Haseltine W, Sodroski J: Attenuation of human immunodeficiency virus type I cytopathic effect by a mutation affecting the transmembrane envelope glycoprotein. J Virol I99I, 65:28I-29I.

78. Liu Y, Liu H, Kim BO, Gattone VH, Li J, Nath A, Blum J, He JJ: CD4independent infection of astrocytes by human immunodeficiency virus type I: requirement for the human mannose receptor. J Virol 2004, 78:4I20-4I33.

79. Kong LY, Wilson BC, McMillian MK, Bing G, Hudson PM, Hong JS: The effects of the HIV-I envelope protein gp I 20 on the production of nitric oxide and proinflammatory cytokines in mixed glial cell cultures. Cell Immunol 1996, I72:77-83.

80. Speth C, Schabetsberger T, Mohsenipour I, Stöckl G, Würzner R, Stoiber H, Lass-Flörl C, Dierich MP: Mechanism of human immunodeficiency virus-induced complement expression in astrocytes and neurons. J Virol 2002, 76:3179-3188.

81. Baggiolini M, Loetscher P, Moser B: Interleukin-8 and the chemokine family. Int J Immunopharmacol 1995, 17:103-108.

82. Falsig J, Pörzgen P, Lotharius J, Leist M: Specific modulation of astrocyte inflammation by inhibition of mixed lineage kinases with CEP-I 347. J Immunol 2004, I 73:2762-2770.

83. Zelenaia O, Schlag BD, Gochenauer GE, Ganel R, Song W, Beesley JS, Grinspan JB, Rothstein JD, Robinson MB: Epidermal growth factor receptor agonists increase expression of glutamate transporter GLT-I in astrocytes through pathways dependent on phosphatidylinositol 3-kinase and transcription factor NFkB. Molec Pharmacol 2000, 57:667-678.

84. Neil SJD, Aasa-Chapman MMI, Clapham PR, Nibbs RJ, McKnight , Weiss RA: The promiscuous CC chemokine receptor D6 is a functional coreceptor for primary isolates of human immunodeficiency virus type I (HIV-I) and HIV-2 on astrocytes. J Virol 2005, 79:9618-9624.

85. Kwong PD, Wyatt R, Robinson J, Sweet RW, Sodroski J, Hendrickson WA: Structure of an HIV gp 120 envelope glycoprotein in complex with the CD4 receptor and a neutralizing human antibody. Nature 1998, 393:648-659.

86. Endres MJ, Clapham PR, Marsh M, Ahuja M, Turner JD, McKnight A, Thomas JF, Stoebenau-Haggarty B, Choe S, Vance PJ, Wells TN, Power CA, Sutterwala SS, Doms RW, Landau NR, Hoxie JA: CD4independent infection by HIV-2 is mediated by fusin/CXCR4. Cell 1996, 87:745-756.

87. Reeves JD, Hibbitts S, Simmons G, McKnight A, Azevedo-Pereira JM Moniz-Pereira J, Clapham PR: Primary human immunodeficiency virus type 2 (HIV-2) isolates infect CD4-negative cells via CCR5 and CXCR4: comparison with HIV-I and simian immunodeficiency virus and relevance to cell tropism in vivo. I Virol 1999, 73:7795-7804.

88. Willett BJ, Adema K, Heveker N, Brelot A, Picard L, Alizon M, Turner JD, Hoxie JA, Peiper S, Neil JC, Hosie MJ: The second extracellular loop of CXCR4 determines its function as a receptor for feline immunodeficiency virus. J Virol 1998, 72:6475-648I.

89. Neumann M, Felber BK, Kleinschmidt A, Froese B, Erfle V, Pavlakis $\mathrm{GN}$, Brack-Werner R: Restriction of human immunodeficiency virus type I production in a human astrocytoma cell line is associated with a cellular block in Rev function. J Virol 1995, 69:2159-2167.

90. Atwood JW, Tornatore SC, Traub R, Conant K, Drew DP, Major EO: Stimulation of HIV type I gene expression and induction of NF-kB (p50/p65)-binding activity in tumor necrosis factor a treated human fetal glial cells. AIDS Res Hum Retr 1994, 10:1207-12111.

91. Demart S, Ceccherini-Silberstein F, Schlicht S, Walcher S, Wolff H, Neumann M, Erfle V, Brack-Werner R: Analysis of nuclear targeting activities of transport signals in the human immunodeficiency virus Rev protein. Exp Cell Res 2003, 291:484-501.

92. Tornatore C, Meyers K, Atwood W, Conant K, Major EO: Temporal patterns of human immunodeficiency virus type I transcripts in human fetal astrocytes. J Virol 1994, 68:93-102.

93. Roberts ES, Burudi EME, Flynn C, Madden LJ, Roinick KL, Watry DD, Zandonatti MA, Taffe MA, Fox HS: Acute SIV infection of the brain leads to upregulation of IL6 and interferon-regulated genes: expression patterns throughout disease progression and impact on neuroAIDS. J Neuroimmunol 2004, 157:8I-92.

94. Salminen MO, Ehrenberg PK, Mascola JR, Dayhoff DE, Merling R, Blake B, Louder M, Hegerich S, Polonis VR, Birx DL, Robb ML, McCutchan FE, Michael NL: Construction and biological characterization of infectious molecular clones of HIV-I subtypes B and $E$ (CRFOI_AE) generated by the polymerase chain reaction. Virology 2000, 278: I03-II0.

95. Potash MJ, Chao W, Bentsman G, Paris N, Saini M, Nitkiewicz J, Belem P, Sharer L, Brooks Al, Volsky DJ: A mouse model for study of systemic HIV-I infection, antiviral immune responses, and neuroinvasiveness. Proc Natl Acad Sci USA 2005, 102:3760-3765.
Publish with Biomed Central and every scientist can read your work free of charge

"BioMed Central will be the most significant development for disseminating the results of biomedical research in our lifetime. "

Sir Paul Nurse, Cancer Research UK

Your research papers will be:

- available free of charge to the entire biomedical community

- peer reviewed and published immediately upon acceptance

- cited in PubMed and archived on PubMed Central

- yours - you keep the copyright
BioMedcentral 